\title{
Investigation of Performance and Rotor Tip Flow Field in a Low Speed Research Compressor with Circumferential Groove Casing Treatment at Varying Tip Clearance
}

\author{
Matthias Rolfes, Martin Lange, and Ronald Mailach \\ Technische Universität Dresden, Institute of Fluid Mechanics, Chair of Turbomachinery and Flight Propulsion, \\ 01062 Dresden, Germany \\ Correspondence should be addressed to Matthias Rolfes; matthias.rolfes@tu-dresden.de
}

Received 16 March 2017; Accepted 1 June 2017; Published 31 July 2017

Academic Editor: Funazaki Ken-ichi

Copyright (C) 2017 Matthias Rolfes et al. This is an open access article distributed under the Creative Commons Attribution License, which permits unrestricted use, distribution, and reproduction in any medium, provided the original work is properly cited.

\begin{abstract}
Experimental investigations in a single-stage low speed axial research compressor are presented. The influence of four different rotor tip clearances on the overall compressor performance and on the rotor tip flow field is investigated in configurations with and without circumferential groove casing treatments. Piezo-resistive pressure transducers are used to capture the unsteady flow field in the rotor tip region. The investigated casing groove is effectively working at the three largest investigated tip clearance sizes. The largest achieved operating range increase by the groove is $6.9 \%$. The groove can delay the upstream movement of the flow interface between leakage flow and main flow and thus increase the stable operating range. Rotating instabilities are shown to exist at large tip clearance sizes in throttled operating conditions. Their amplitudes can be damped by the casing groove. No modal activities could be detected in the current single-stage compressor build.
\end{abstract}

\section{Introduction}

The relative motion between blades and casing dictates the necessity of radial clearances in an axial compressor. It is commonly known that an increase in tip clearance to chord ratios decreases pressure ratio, efficiency, and normally operating range of an axial compressor; see, for example, Wisler [1] and Cumpsty [2]. In service, the clearance ratios of a gas turbine's axial compressor are normally not constant but change due to wear, transient operations, and thermal expansions. Moreover, the minimum absolute clearance level can also be constrained by different thermal expansions of the components. As modern compressors tend to have very high pressure ratios, the last stages have very small blade heights which, together with the above-mentioned constraints, leads to larger clearance ratios here. The use of wide-chord blades is not able to totally compensate for this effect. These observations underline the fact that axial compressors at least partially run with tip clearances that are greater than favored by aerodynamic, which lead to the above-mentioned performance penalties.
One possible means to recover a loss in operating range due to a tip clearance increase is the use of circumferential groove casing treatments. Their simplicity and ease of installation put them in the focus of research for several decades. In the 1970s several experimental works [3-5] showed the general effectiveness of circumferential groove casing treatments. It is also in this early period that the potential of grooves to reduce the sensitivity towards large tip clearances has been proven. One example for a more recent investigation on circumferential groove CTs using CFD methods is the work by Shabbir and Adamczyk [6]. The authors showed that the flow of the compressor is stabilized by a momentum exchange between groove and main passage flow and furthermore that grooves reduce the aerodynamic blockage near the rotor tip. Concerning the working mechanism of casing groove some authors, for example, Lu et al. [7], Perrot et al. [8], and Rolfes et al. [9], showed that grooves work by delaying the upstream movement of the flow interface between tip leakage flow and passage flow and therefore shift the point where spill-over of leakage flow occurs towards lower mass flows. On the other hand, Houghton and Day [10] and Li et al. [11] showed 


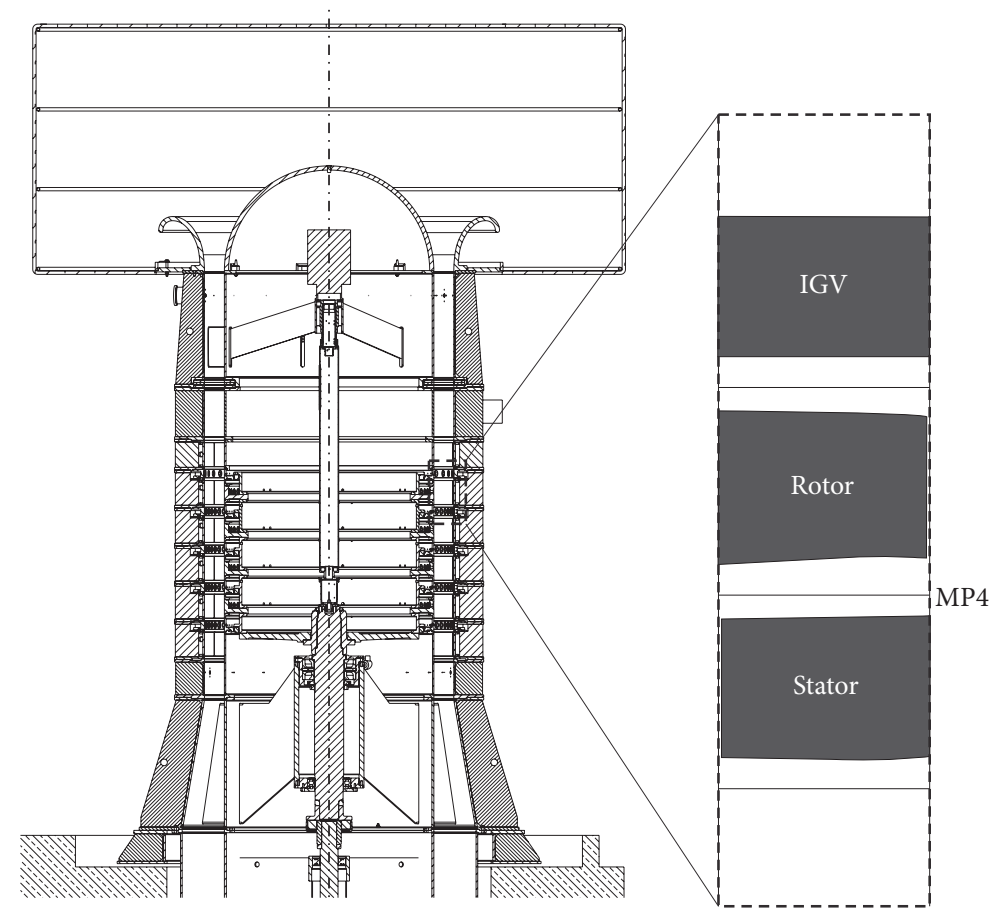

FIGURE 1: LSRC Dresden, cross section of single-stage build.

that the influence of the flow interface is not mandatory for a well working circumferential groove. This shows that the working mechanism of circumferential groove is still not universally understood and that different mechanisms might exist.

Compressor stability, the reason for surge or stall and the way towards it, is in the focus of interest since compressors in gas turbines became widely used. A very detailed overview of research in this field is given by Day [12]. Mailach et al. [13] and März et al. [14] investigated the highly controversial field of rotating instabilities (RI) within the topic of compressor stability. Mailach et al. found out that the observed disturbances are called forth by periodic fluctuations of the tip leakage vortex. Other authors, for example, Wisler et al. [15], connect the occurrence of RI in Mailach et al. to the fact that one stage of the four-stage compressor has been weakened by a tip clearance increase. Young et al. [16], however, found similar disturbances as Mailach et al. and März et al. that rotated relative to the rotor under near stall conditions in their investigated single-stage compressor with large tip clearance. According to Camp and Day [17] compressor stall can be caused by a local (mostly in the rotor tip) flow breakdown, the so called spikes, in only one or two blade passages that grow into stall cells. The authors also found modal oscillations that exist long before stall and are characterized by flow field oscillations of a wavelength of the compressor circumference or half the circumference. Modes are not directly linked with compressor stall, but can grow into a stall cell with further throttling. These authors concluded that modes appear when the compressor stalls with a positively (or zero) sloped characteristic and spikes when the characteristic is negatively sloped at stall.
In this paper a single-stage low speed axial compressor with and without casing grooves at four different rotor tip clearances is investigated. Besides overall performance, the influence of tip clearance increases and casing groove on the rotor tip flow field is shown. Their influence on rotating instabilities and modal oscillations will also be addressed to increase understanding of these phenomena.

\section{Test Compressor and Measurement Techniques}

The investigations have been performed on the Low Speed Research Compressor at Technische Universität Dresden. The reference configuration of the LSRC consists of 4 stages. One characteristic of the compressor is its vertical arrangement. The air passes 4 repeating stages from top to bottom. Different operating points are set by a throttle in the basement. The cross section of the compressor is shown in Figure 1 and reference build parameters can be found in Table 1. Boos et al. [18] and Künzelmann et al. [19] presented detailed information about the compressor installation and measurement results for the reference build. For the investigation at hand the compressor has been installed in a singlestage configuration. Different tip clearances were realized by milling the compressor blades to the desired height. Four rotor tip clearances were investigated. The smallest tip clearance (TC) is $s / c=1.2 \%$ and has been increased to $s / c=$ $2.5 \%, s / c=3.7 \%$, and $s / c=5.0 \%$. Stator hub clearance has been kept constant at $s / c=2.1 \%$. The installed blading has been the same as in Rolfes et al. [9]. It has been designed by ALSTOM Power to model the rear stages of a high pressure compressor of a state of the art gas turbine. 
TABLE 1: Data of the LSRC reference build.

\begin{tabular}{lc}
\hline Casing diameter & $1500 \mathrm{~mm}$ \\
Hub-to-tip ratio & 0.84 \\
Blade count IGV & 51 \\
Blade count rotor & 63 \\
Blade count stator & 83 \\
Chord length rotor, MS & $110 \mathrm{~mm}$ \\
Chord length stator, MS & $89 \mathrm{~mm}$ \\
Solidity of rotor blades, tip & 1.55 \\
Mass flow, DP & $\dot{m}=25.35 \mathrm{~kg} / \mathrm{s}$ \\
Reynolds number rotor inlet, MS & $\mathrm{Re}=5.7 \cdot 10^{5}$ \\
Mach number rotor inlet, MS & $\mathrm{Ma}=0.22$ \\
\hline
\end{tabular}

DP: design point; MS: midspan.

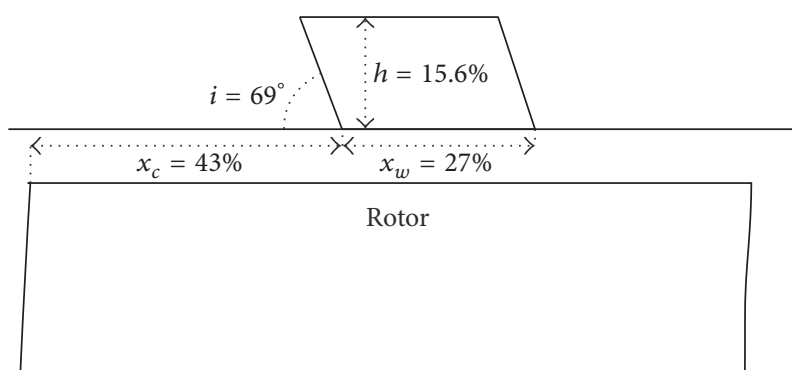

FIGURE 2: Geometry of circumferential casing groove.

The geometry of the circumferential casing groove is depicted in Figure 2. The performance of the compressor with $s / c=5.0 \%$ and this groove has already been described in Rolfes et al. [9].

This paper presents the characteristics of the compressor and results from unsteady wall pressure measurements with piezo-resistive pressure transducers which were installed flush in the rotor casing. All measurements were performed at design speed of $1000 \mathrm{rpm}$ at standard conditions.

Compressor characteristics are composed of 11 throttle positions from open throttle to stall. At each of these positions the stator vanes are traversed in 57 uniformly distributed steps over two pitches. These data are arithmetically averaged to form one point on the speed line. The overall pressure rise is determined with an accuracy of $\pm 0.02 \%$ by 12 casing static pressure taps in the exit plane and 6 casing static pressure taps in the inlet plane of the compressor. To calculate the total pressure ratio, the total pressures in the inlet and exit planes are derived by an iterative procedure from the static values by the assumption of a perfect gas. Thus, the curves of the total pressure ratio presented in this paper are derived from casing static pressure taps. To calculate the efficiency, data from a high-precision torquemeter (accuracy $0.01 \%$ full-scale at $5000 \mathrm{Nm}$ ) are used which results in a measuring accuracy of the efficiency of \pm 0.2 percentage points (representing the $95 \%$ confidence interval). Total temperature at the inlet of the compressor is measured via 8 resistance thermometers in the filter cage. In the exit plane 6 total temperature probes equipped with

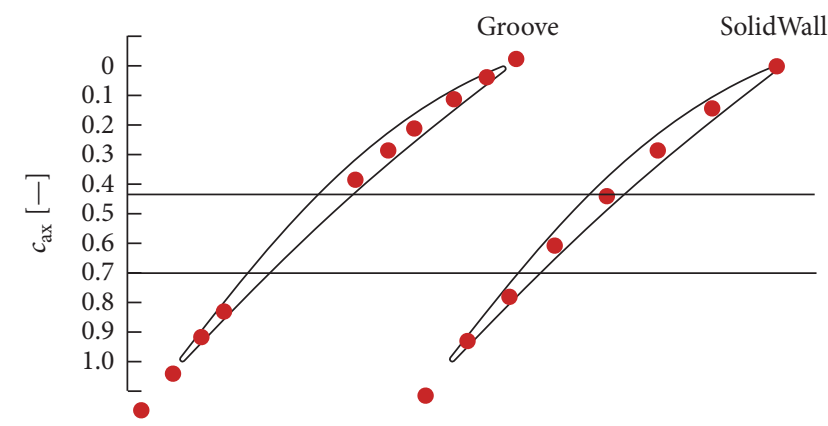

FIGURE 3: Arrangement of pressure transducers over rotor, left: Groove, right: SolidWall.

a thermocouple are equally spaced around the compressor circumference. Enthalpy is derived from the measured quantities of temperature and pressure by the assumption of a perfect gas. The stall point of the compressor has been explicitly tested for each configuration. The performance parameters of the compressor characteristics are calculated as follows:

$$
\eta=\frac{\dot{m}_{\text {in }} \cdot\left(h_{\text {total,is,out }}-h_{\text {total,in }}\right)}{M \cdot 2 \pi n}
$$

isentropic efficiency

$$
\xi=\frac{\dot{m}_{\mathrm{in}} \cdot \sqrt{T_{\text {total,in }}} / p_{\text {total }}}{\dot{m}_{\mathrm{in}, \mathrm{DP}} \cdot \sqrt{T_{\text {total,in,DP }}} / p_{\text {total,DP }}}
$$

flow rate coefficient

$$
\begin{aligned}
\pi_{t} & =\frac{p_{\text {total,out }}}{p_{\text {total,in }}} \text { total pressure ratio } \\
\Psi_{t-s} & =\frac{2 \cdot\left(p_{\text {out }}-p_{\text {total,in }}\right)}{u_{\mathrm{MS}}^{2} \cdot \rho}
\end{aligned}
$$

total-to-static pressure coefficient

$\phi=\frac{v_{\mathrm{ax}}}{u} \quad$ flow coefficient.

Mounting piezo-resistive pressure sensors flush with the rotor casing allows the unsteady wall pressure over the rotor to be captured. For these measurements the stator vanes have been traversed in 21 steps over one pitch. The arrangement of the transducers along the blade chord can be found in Figure 3. The left hand side shows the sensors for the groove configuration and the right hand side that of the solid wall configuration. For clarity, the limits of the circumferential groove are plotted on both sides.

The standard deviation of the unsteady wall pressure, which is used in the presentation of the results, is defined as follows:

$$
\sigma_{p}=\sqrt{\frac{1}{N} \sum_{i=0}^{N-1}\left(p_{i}(t)-\langle p(t)\rangle\right)^{2}} .
$$




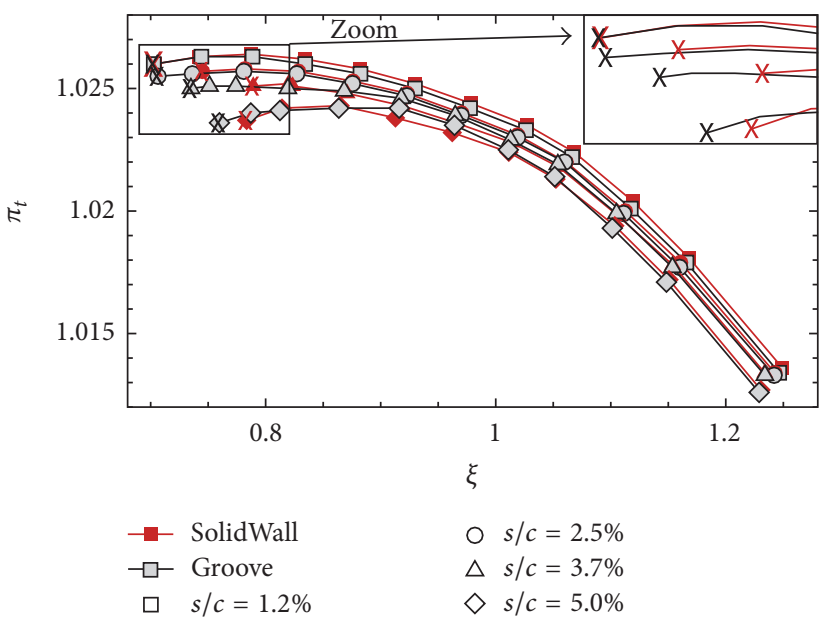

(a)

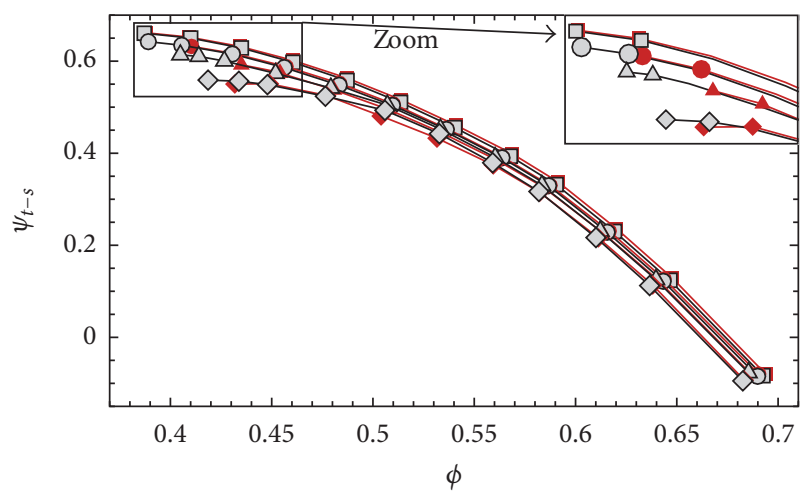

(b)

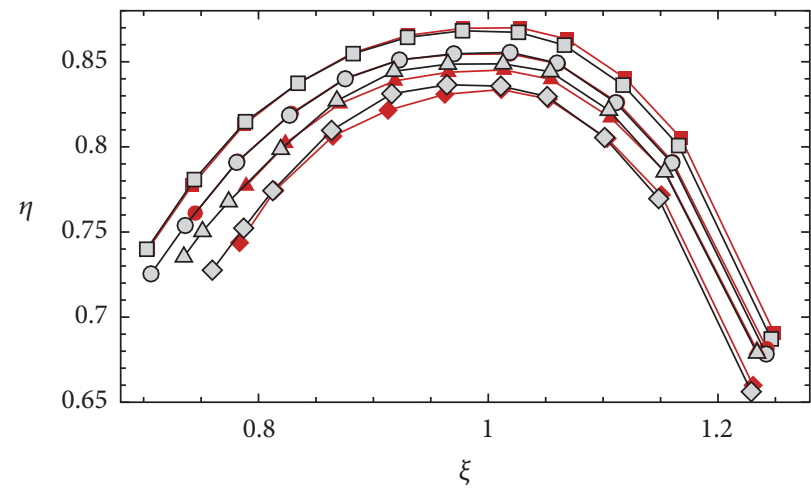

(c)

Figure 4: Compressor characteristics: (a) total pressure ratio, (b) total-to-static pressure coefficient, and (c) efficiency.

Here, $p_{i}$ is the current pressure value, $N$ is the number of revolutions, and $\langle p(t)\rangle$ is the ensemble-averaged pressure value.

\section{Results}

3.1. Compressor Characteristics. The compressor characteristics for all four tip clearance sizes are plotted in Figure 4. The throttle settings are identical between each configuration. Figure 4(a) shows the total pressure ratio over flow rate coefficient. In this part of the figure, the last stable operating points are marked by an $X$ to better distinguish the stall points between SolidWall and Groove. The zoomed region has the same intention. Figure 4(c) shows isentropic efficiency over flow rate coefficient and the total-to-static pressure coefficient is plotted over flow coefficient in Figure 4(b). Here, the zoomed region only shows symbols for the last two measured points on the characteristic curve to simplify the identification of the slopes of the characteristics. The flow coefficients of the stall point and the percentage reduction in stall mass flow due to the Groove can be found in Table 2 for all tested configurations.

At the smallest tip clearance of $s / c=1.2 \%$ the compressor has the highest total pressure ratio and efficiency due to
TABLE 2: Stalling flow coefficients and percentage reduction of stall mass flow for each configuration.

\begin{tabular}{lccc}
\hline$s / c$ & Configuration & $\phi_{\text {Stall }}$ & $\Delta \dot{m}_{\text {Stall }}$ \\
\hline \multirow{2}{*}{$1.2 \%$} & SolidWall & 0.388 & $0 \%$ \\
& Groove & 0.387 & \\
$2.5 \%$ & SolidWall & 0.410 & $5.1 \%$ \\
& Groove & 0.389 & \\
$3.7 \%$ & SolidWall & 0.435 & $6.9 \%$ \\
& Groove & 0.405 & \\
$5.0 \%$ & SolidWall & 0.432 & $3.0 \%$ \\
& Groove & 0.419 & \\
\hline
\end{tabular}

the lowest tip leakage flow loss. The Groove is not able to positively influence either total pressure ratio, efficiency, or stall mass flow (see Table 2) at this tip clearance size. At flow rate coefficients close to stall Groove and SolidWall show nearly identical total pressure ratios and efficiencies whereas at flow rates higher than design $(\xi \geq 1.0)$ both are slightly reduced by Groove. One reason for the lack of operating range increase can be that the rotor is not tip-critical in this configuration. 
As expected, an increase of tip clearance to $s / c=2.5 \%$ leads to a loss in total pressure ratio and efficiency and an increase in stall mass flow. The casing treatment obviously starts working at this size of tip clearance. With the casing treatment the stall mass flow is reduced by $5.1 \%$ (Table 2). The compressor is now able to run at a flow rate coefficient as low as that of SolidWall of the smallest tested tip clearance size $s / c=1.2 \%$. The Groove configuration still shows a small reduction in total pressure ratio which, however, is smaller than at $s / c=1.2 \%$. Isentropic efficiency is not decreased by the Groove at this size of tip clearance.

With further increased tip clearance to $s / c=3.7 \%$ total pressure ratio, efficiency, and operating range decrease. The Groove remains effective and decreases the minimum flow rate coefficient by $6.9 \%$ compared to SolidWall at the same clearance level, which can be seen in Table 2. Groove at this tip clearance size now even reaches a slightly lower minimum mass flow than SolidWall of $s / c=2.5 \%$. The highest decrease of flow rate coefficient leads to the assumption that the Groove is most effective at this clearance configuration. Another distinctive feature in this configuration is the increase in total pressure ratio and efficiency in regions $0.85<\xi<1.1$

The last tip clearance increase to $s / c=5.0 \%$ leads to a stronger decreasing total pressure rise and efficiency of SolidWall near stall than in the steps of tip clearance increase before. Furthermore, the stall mass flow of SolidWall has not been increased in contrast to $s / c=3.7 \%$ but has been slightly reduced. This behavior is reproducible and has been measured several times. The Groove, however, is still able to decrease the minimum stall mass flow by $3 \%$ (Table 2). The Groove increases efficiency in the region from $\xi=1.1$ to stall by a maximum of $1 \%$.

According to Camp and Day [17] and Day [12] the total-to-static characteristics are helpful to identify the type of stall inception. With a negatively sloped total-to-static characteristic stall is likely to occur by spikes whereas a zero slope indicates modal stall inception. The total-tostatic pressure coefficient clearly shows negative slopes at tip clearance sizes of $s / c=1.2 \%, s / c=2.5 \%$, and $s / c=3.7 \%$ for both SolidWall and Groove, which can be seen in the zoomed region in Figure 4(b). Here, stall is likely to occur via spikes. The largest tip clearance configuration however shows a zero slope near stall for SolidWall and thus, according to Camp and Day, possible modal activities. The Groove configuration of $s / c=5.0 \%$, however, shows again a negative slope.

It is noteworthy that the zero slope of the total-to-static characteristics occurs at the tip clearance size that showed no increase in stall mass flow compared to the next smaller tip clearance.

The following is an addition to a comparison of different investigations in open literature that has been presented by Berdanier and Key [20]. They plotted the percentage increase in stall flow coefficient relative to the smallest tested tip clearance size $\Delta \phi_{\text {Stall }}$ over tip clearance size for results from Wisler [1], McDougall [21], and their own test results. In Figure 5, which is based on Berdanier and Key, the data from the present paper are added as well as data of both compressors A and B from Wisler et al. [15]. The clearance

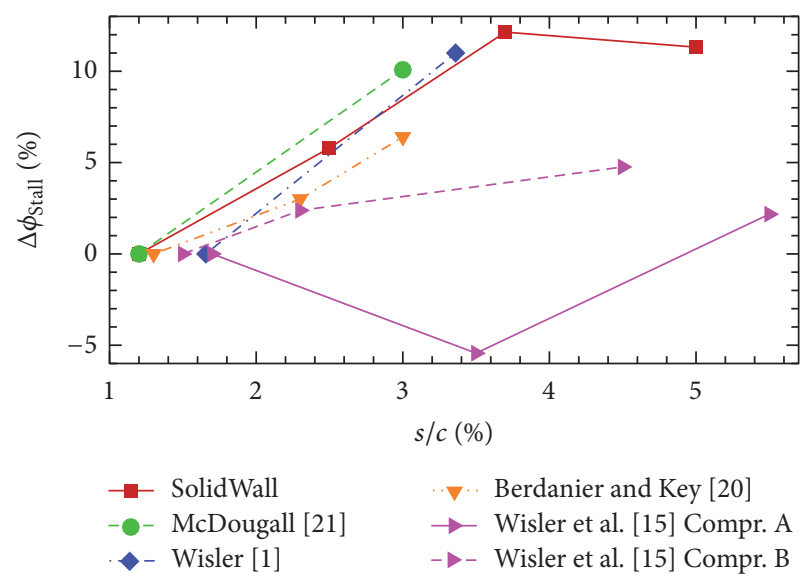

FIGURE 5: Stalling flow coefficient at different tip clearance sizes.

TABLE 3: Clearance derivatives of different investigations.

\begin{tabular}{lc}
\hline \multirow{2}{*}{ Investigation } & Clearance derivative \\
\hline Wisler [1] & $\delta$ \\
\hline McDougall [21] & 6.5 \\
\hline Berdanier and Key [20] TC1-2 & 5.6 \\
Berdanier and Key [20] TC2-3 & 3.0 \\
\hline Wisler et al. [15] Compr. A TC1-2 & 4.8 \\
Wisler et al. [15] Compr. A TC2-3 & -3.0 \\
\hline Wisler et al. [15] Compr. B TC1-2 & 3.8 \\
Wisler et al. [15] Compr. B TC2-3 & 3.0 \\
\hline Present Paper TC1-2 & 1.1 \\
Present Paper TC2-3 & 4.5 \\
Present Paper TC3-4 & 5.3 \\
\hline
\end{tabular}

derivative $\delta$ (the increase in stall flow coefficient per $1 \%$ clearance increase) that has also been discussed by Berdanier and Key is shown in Table 3 for the same test cases as in Figure 5. Some of the investigations tested more than two tip clearance sizes, so the derivatives for each step of tip clearance increase are listed (TC1-2, e.g., is the first step of tip clearance increase of the particular investigation).

The increase in stall mass flow that resulted from a tip clearance increase from $s / c=1.2 \%$ to $2.5 \%$ (TC1-2) and from $s / c=2.5 \%$ to $3.7 \%$ (TC2-3) in the present paper fits well into the data presented by Berdanier and Key. The clearance derivatives of 4.5 and 5.3, respectively, are within the range of 3 to 6 that the other investigations show. This increase in clearance derivative from TC1-2 to TC2-3 has also been shown by Berdanier and Key for their compressor. The last tested tip clearance increase from $s / c=3.7 \%$ to $5.0 \%$ (TC3-4) in this paper, however, shows a remarkably different behavior because the stall mass flow is not increased but decreased and hence the derivative is -0.6 . This behavior has not been detected by $[1,20,21]$ because their largest tip clearance size is notably lower than the largest tested tip clearance size in this paper. Wisler et al. [15] tested two compressors A and B with largest tip clearance sizes of $s / c=5.5 \%$ and $s / c=4.5 \%$, 


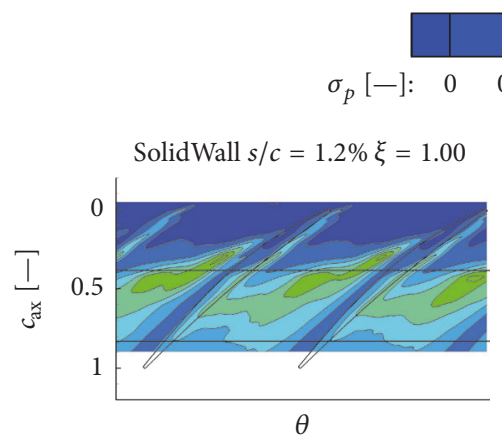

(a)

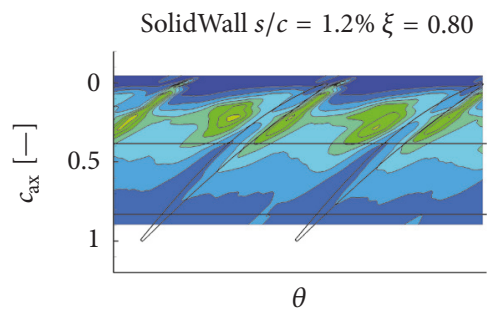

(b)

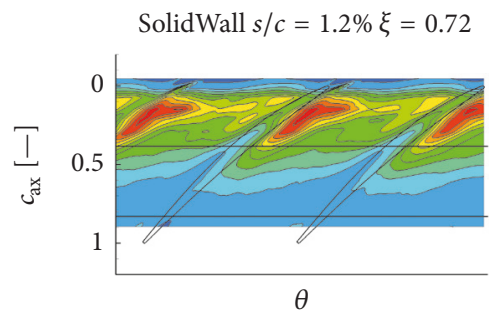

(c)

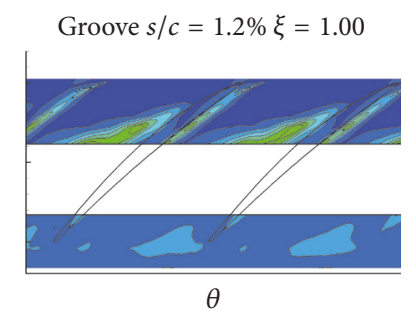

(d)

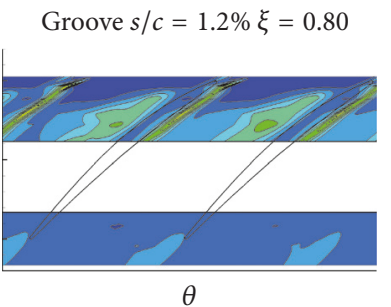

(e)

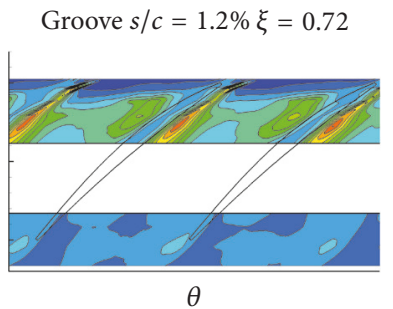

(f)

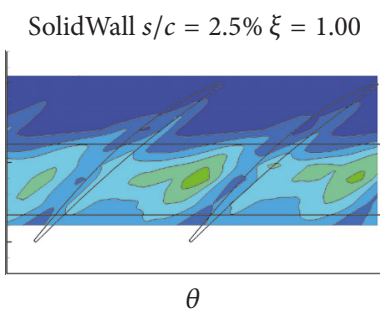

(g)

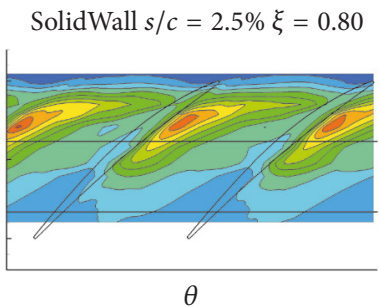

(h)

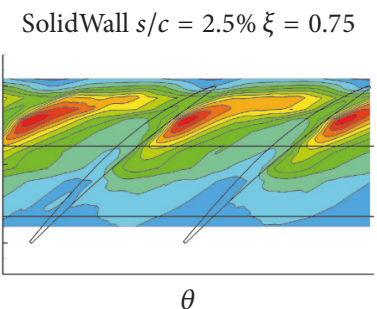

(i)

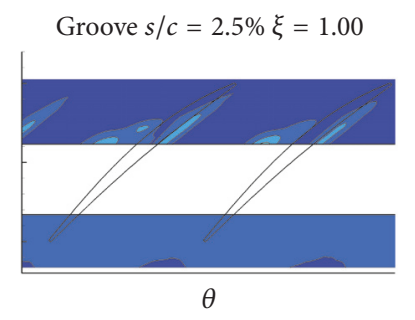

(j)

Groove $s / c=2.5 \% \xi=0.80$

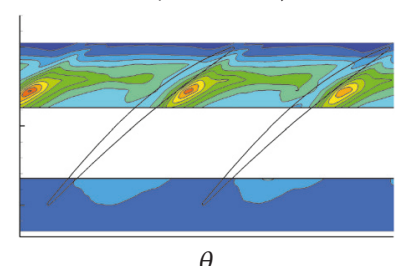

(k)

Groove $s / c=2.5 \% \xi=0.71$

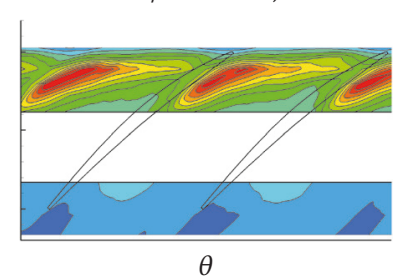

(1)

FIGURE 6: Standard deviation of casing static pressure over rotor for SolidWall and Groove at $s / c=1.2 \%$ and $s / c=2.5 \%$ at three different operating points $((\mathrm{a}, \mathrm{d}, \mathrm{g}, \mathrm{j})$ : design point, $(\mathrm{b}, \mathrm{e}, \mathrm{h}, \mathrm{k})$ : throttled operating point, and (c, f, i, l): near stall of current configuration).

respectively. Both compressors show a different behavior than the results presented before. Compressor A shows at TC1-2 a decrease in stall mass flow which results in a clearance derivative of -3 . According to Wisler et al. stability in compressor A is limited by tip and hub blockage whereas compressor B is more sensitive to tip blockage and therefore has a derivative of 3 at TC1-2. These results show that the clearance derivative is strongly dependent on the investigated compressor and that effects like a shift of the stall mechanism (either from hub to tip or possibly from rotor to stator) with tip clearance can also play a dominant role. The second tip clearance increase of compressor B in [15] shows a derivative of only 1.1. One could speculate that this reduced derivative of TC2-3 compared to TC1-2 hints to a similar behavior as in the present paper, a negative derivative at larger tip clearances. It is however not visible due to the limited number of investigated tip clearance sizes in [15] that result in an almost doubling of tip clearance size from TC1-2 to TC2-3. Thus, the fact that other investigations do not show a negative clearance derivative at larger tip clearances might be also due to a relatively low resolution between tightest and largest clearance.
The information from the present investigation is a valuable addition to data in open literature. It confirms the findings of Berdanier and Key [20] and add new information for tip clearances larger than $s / c=4 \%$.

3.2. Wall Pressure over Rotor. The following section deals with the results of the unsteady wall pressure measurements over the rotor.

The standard deviation of the static wall pressure $\left(\sigma_{p}\right)$ is plotted over two rotor pitches in Figure 6 for $s / c=1.2 \%$ and $s / c=2.5 \%$ and in Figure 7 for $s / c=3.7 \%$ and $s / c=$ $5.0 \%$. Results for SolidWall and Groove are shown at three different operating points, the design point $(\xi=1.00)$, a throttled operating point $(\xi=0.80)$, and a near stall operating point of the respective configuration. Due to brevity, at $s / c=$ $5.0 \%$ the operating points that are shown for the SolidWall configuration are only the design point and $\xi=0.80$. Because it is not possible to place sensors in the Groove region on the casing radius, the Groove results show a blank space. This region is also indicated by horizontal black lines in the SolidWall results. In the presented plots, high values of 


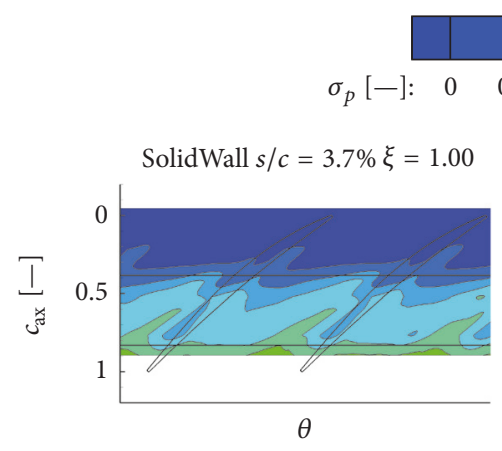

(a)

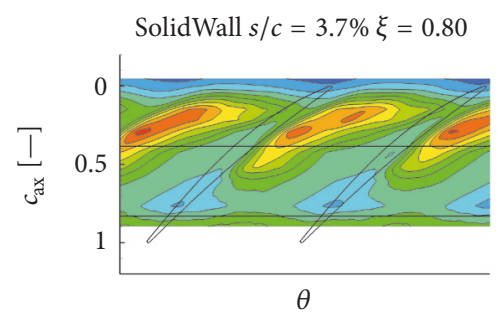

(b)

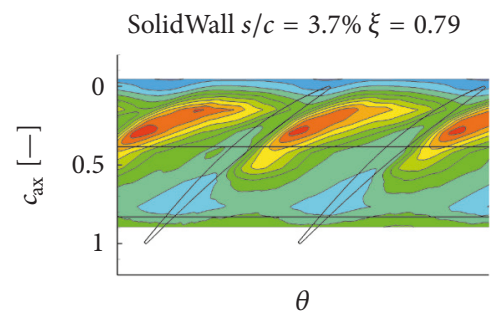

(c)

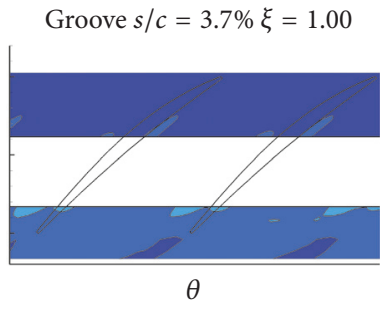

(d)

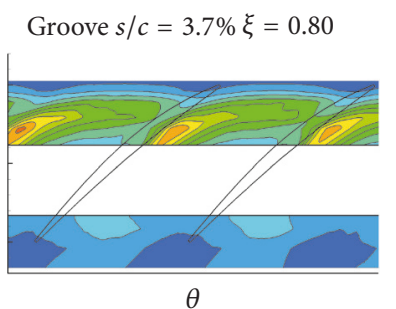

(e)

Groove $s / c=3.7 \% \xi=0.74$

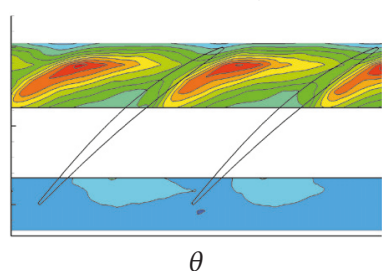

(f)

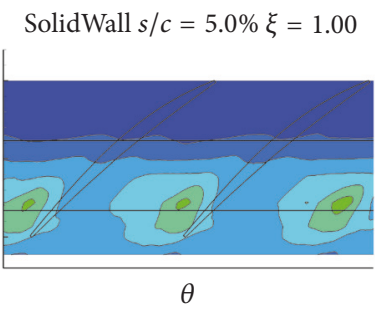

(g)

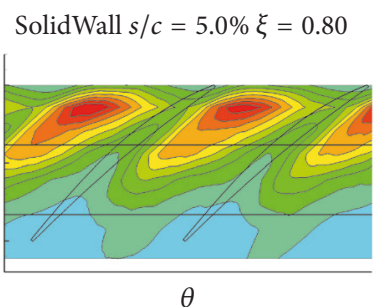

(h)
Groove $s / c=5.0 \% \xi=1.00$

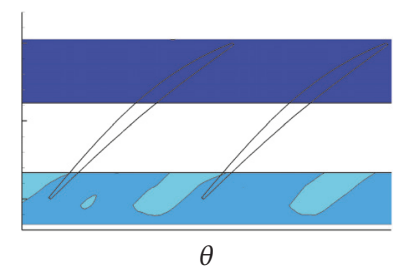

(i)

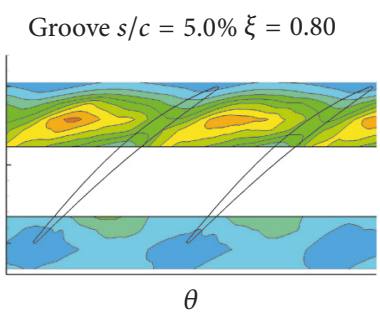

(j)

Groove $s / c=5.0 \% \xi=0.77$

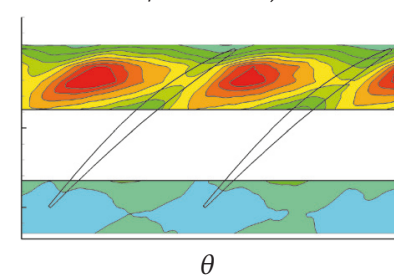

(k)

Figure 7: Standard deviation of casing static pressure over rotor for SolidWall and Groove at $s / c=3.7 \%$ and $s / c=5.0 \%$ at three different operating points $((\mathrm{a}, \mathrm{d}, \mathrm{g}, \mathrm{i})$ : design point, $(\mathrm{b}, \mathrm{e}, \mathrm{h}, \mathrm{j})$ : throttled operating point, and $(\mathrm{c}, \mathrm{f}, \mathrm{k})$ : near stall of current configuration).

standard deviation can be found in regions where the tip leakage vortex interacts with the main flow.

3.2.1. $s / c=1.2 \%$. At the design point of SolidWall (Figure 6(a)) high standard deviations (and thus the tip leakage vortex) start near the suction side of the blade around $c_{\mathrm{ax}}$ $=0.2$. The vortex expands into the passage and in a region around $c_{\mathrm{ax}}=0.6$ it reaches the pressure side of the opposite blade. With increased throttling (Figure 6(b)) the region of high standard deviation moves upstream towards the leading edge. The vortex now travels towards the pressure side of the opposite blade in the front half of the blade and reaches it at approximately $c_{\mathrm{ax}}=0.25$. This means that also the vortex inclination against axial direction is increased. At the last stable operating point (Figure 6(c)) the upstream boundary of the tip leakage vortex is nearly vertical. The highest standard deviations can be found near the pressure side of the opposite blade, indicating a strong vortex fluctuation in this area. The increase in standard deviation from design point to near stall can be attributed to an increase in vortex strength with throttling.

At the design point of Groove (Figure 6(d)) vortex size and position are in the same region as in the SolidWall configuration. A manipulation of the vortex by the Groove cannot be detected under these operating conditions. At $\xi=0.80$ (Figure 6(e)) differences between SolidWall and Groove occur. The values of high standard deviation near the blade pressure side are reduced in contrast to the SolidWall and the values of $\sigma_{p}$ are lower in the passage. At the near stall operating point, the Groove's influence is enhanced. The standard deviations in the whole region upstream the Groove are lower than in the SolidWall configuration. The inclination of the upstream boundary of the tip leakage vortex has also been lowered. Despite the fact that the Groove influences the near casing flow field at the smallest tip clearance configuration, the Groove is not able to reduce the stall mass flow; see Figure 4. This underlines the previous assumption that stall at $s / c=1.2 \%$ is not triggered by the near casing flow in the rotor.

3.2.2. $s / c=2.5 \%$. With increasing tip clearance to $s / c=2.5 \%$ the tip leakage vortex at the design point (Figure 6(g)) now starts more downstream around $c_{\mathrm{ax}}=0.3$. The region where the vortex reaches the pressure side is nearly unchanged in comparison with the next smaller tested tip clearance size. The Groove (Figure 6(j)) does not influence the starting point 
of the vortex at $\xi=1.00$. At throttled operation in Figure 6(h) the vortex inclination has increased notably, as before. High values of $\sigma_{p}$ can be found near the pressure side of the opposite blade around $c_{\mathrm{ax}}=0.3$. At the near stall operating point (Figure 6(i)) these values are further increased and the upper boundary of the tip leakage vortex is nearly vertical and blocks the whole near casing passage. This is in good agreement with one of Vo et al.s [22] criteria for rotating stall onset, the spill-over of leakage fluid into the neighboring passage. The influence of the Groove can again be seen at the two last operating points (Figures $6(\mathrm{k})$ and $6(\mathrm{l})$ ). The upper boundary of the tip leakage vortex at $\xi=0.80$ is more downstream than in the SolidWall case and the standard deviations have been reduced. At the near stall operating point of Groove (which is 4 percentage points lower than that of SolidWall) a similar near casing flow pattern as in the SolidWall case (Figure 6(i)) exists. Thus, the Groove has been able to delay the upstream movement of the tip leakage vortex with throttling. The compressor can be throttled more intensely before the interface between the incoming flow and the tip leakage flow reaches the leading edge and causes a spill-over of leakage flow into the neighboring passage.

3.2.3. $s / c=3.7 \%$. The next tip clearance increase results at the design point (Figure $7(\mathrm{a})$ ) in a further downstream movement of the point of vortex formation to approximately $c_{\mathrm{ax}}=$ 0.4 . In contrast to the two smaller tested tip clearance sizes, high standard deviations can be found in the passage over the whole circumference and the exact point of the interaction of the vortex with the opposite blade cannot be detected. It can be seen that the Groove lies directly in the region of vortex formation and is expected to influence it. Directly downstream the Groove the standard deviation is notably smaller than in the SolidWall configuration. This underlines the above-stated assumption of a Groove's influence on the vortex formation. The lower values of standard deviation upstream the Groove in Figure 7(d) compared to the SolidWall are also attributed to the Groove's influence on the vortex. A reduction of vortex related blockage by the Groove is likely to have a positive upstream influence on the flow field. The throttled operating point of SolidWall in Figure 7(b) is at this clearance size already quite close to the near stall operating point. Thus the upper boundary of the tip leakage vortex is already placed near the blade leading edge. A similar pattern of standard deviation as in $s / c=2.5 \%$ (Figure $6(\mathrm{~h})$ ) is observed. A little further throttling to $\xi=0.79$, shown in Figure 7(c), moves the upper boundary of the tip leakage vortex further upstream and is expected to cause spill-over of leakage fluid and thus to limit the stable operation. The Groove influence (Figures $7(\mathrm{e})$ and $7(\mathrm{f}))$ is also similar to the next smaller tested $s / c$ configuration. The delay of the upstream movement of the above-mentioned interface, which can be seen at $\xi=0.8$ makes the compressor more stable in the rotor tip region and allows in this case an operation at flow rate coefficients that are lower by 5 percentage points in contrast to the SolidWall.

3.2.4. $s / c=5.0 \%$. At the largest tested tip clearance, the tip leakage vortex of SolidWall at the design point (Figure 7(g)) starts again more downstream than at $s / c=3.7 \%$. The starting point now approximately lies at $c_{\mathrm{ax}}=0.5$. This far downstream position of the starting point prevents an impingement of the vortex on the pressure side of the next blade. The Groove configuration at the design point (Figure 7(i)) shows a reduction of standard deviations downstream the Groove. The region of enhanced $\sigma_{p}$ shows, in addition, a reduced spread in circumferential direction due to the Groove. This again shows the influence of the Groove on the near casing flow field. Due to the small difference between $\xi=0.79$ and $\xi=0.80$ (Figures $7(\mathrm{c})$ and $7(\mathrm{~b}))$ at $s / c=3.7 \%$, here only the operating point $\xi=0.80$ is shown in Figure 7(h). As in the configurations before, the upper boundary of tip leakage flow reaches the leading edge and causes stall at a slightly higher throttling. The mechanism of operating range improvement of Groove is also identical to the tip clearance sizes before. At $\xi=0.80$, Figure $7(j)$, the vortex is less intensely inclined than at the SolidWall. At the near stall operating point, Figure 7(k), the upper vortex boundary reaches the leading edge, as in the near stall point of SolidWall.

3.3. Frequency Analysis. In this section a frequency analysis of wall pressure sensors is performed in order to find hints for rotating instabilities that have been found by Mailach et al. [13] in a different build of the same compressor that is investigated in this paper. Mailach et al. weakened the third stage of a four-stage build by locally increasing the tip clearance of the third rotor. At a tip clearance of $s / c=4.3 \%$ their frequency spectra showed typical humps at one-third of blade passing frequency that have been attributed to a fluctuating tip leakage vortex. It is now interesting to find out if these fluctuations also happen in a single-stage compressor with enlarged tip clearance or only in a weakened stage of a multistage compressor, where the weakened stage is stabilized by the surrounding stages and can therefore be operated at lower flow rate coefficients than the similar single-stage.

Frequency spectra of wall pressure sensors at $c_{\mathrm{ax}} \approx 0.125$ are shown in Figure 8 for all tested tip clearance sizes at the throttled operating point. At $\xi=1.00$ none of the four tested clearance sizes shows any activities at frequencies lower than BPF; therefore these results are omitted. For the smallest tested clearance this can also be observed at the throttled operating point. This is in good agreement with Mailach et al., who showed that RI only occur in the throttled operating region of a compressor with relatively large tip clearance size. At $s / c=2.5 \%$, however, a rise of amplitudes in the region $0.4-0.5$. BPF can be seen at $\xi=0.80$ for the SolidWall. This is a first sign that rotating instabilities, as Mailach et al. called the fluctuations of the tip leakage vortex, occur in this compressor build. The rise in amplitudes is also visible for Groove but in a lower extent. It seems that the Groove is able to damp the observed fluctuations.

The throttled operating points of the two largest clearances again show increasing amplitudes below BPF. At $s / c$ $=3.7 \%$ the SolidWall shows amplitudes below BPF that are nearly twice as high as in the next smaller tip clearance configuration. The frequencies, where the high amplitudes occur, are shifted towards lower values, compared with $s / c=$ $2.5 \%$, and are now in the region of $0.35-0.45$. BPF. Here, it is now very obvious that the Groove is able to damp the high 

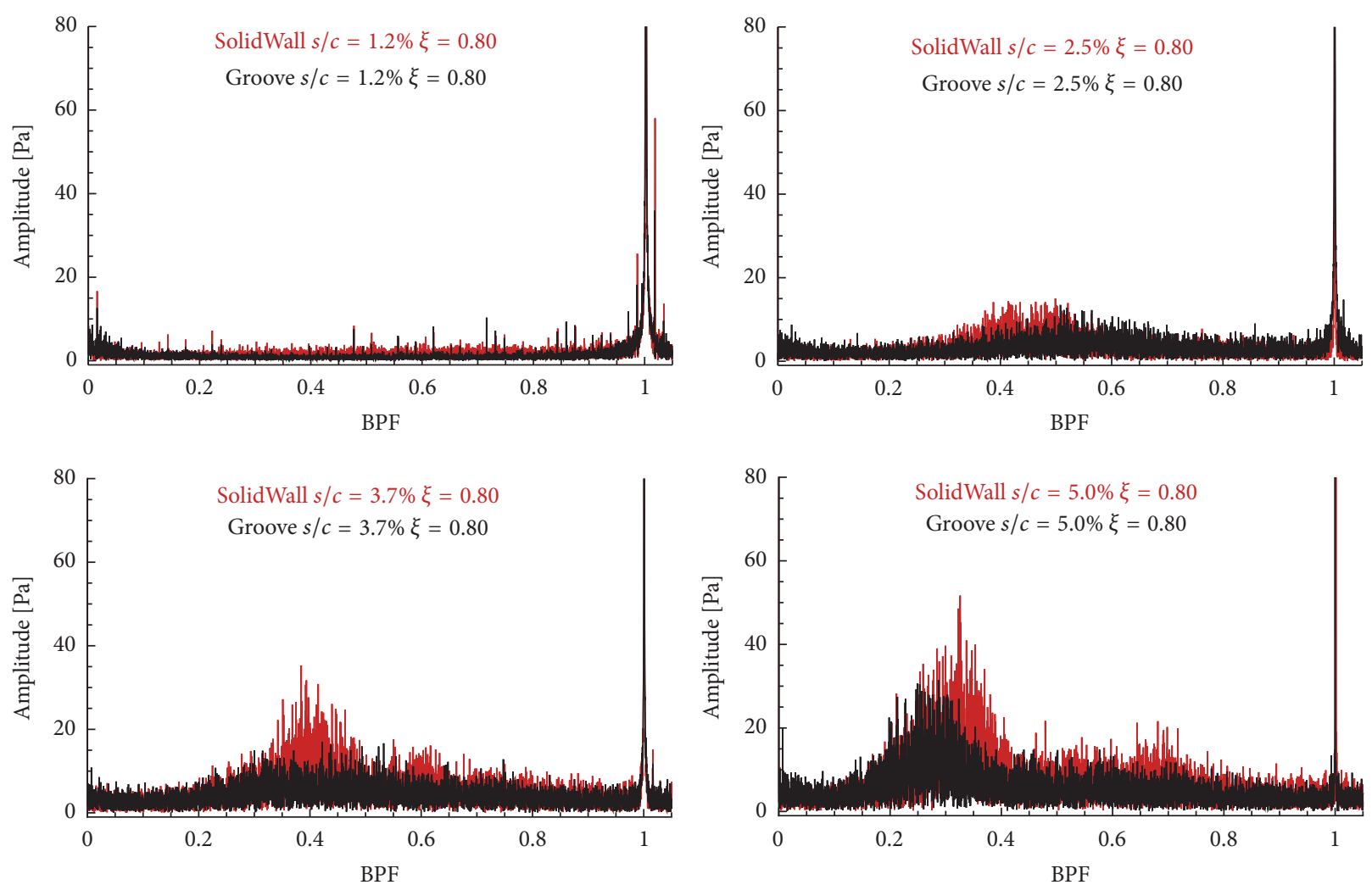

FIGURE 8: Frequency spectra of wall pressure sensor at $c_{\mathrm{ax}} \approx 0.125$ for SolidWall and Groove at the throttled operating point for $s / c=1.2 \%$, $2.5 \%, 3.7 \%$, and $5.0 \%$.

amplitudes. The largest clearance shows a further increase in low frequency amplitudes and a further shift of these frequencies that now lie in a region of $0.3-0.4 \cdot \mathrm{BPF}$. In this operating point a second hump is visible at around $0.7 \cdot \mathrm{BPF}$ which is probably a modulation of the hump around $0.3-0.4$. $\mathrm{BPF}$ and the BPF itself. Looking at the Groove configuration, the damping of the low frequency hump can be seen again.

In the frequency spectra, that are presented in Figure 8, the RI show amplitudes that are relatively small with up to $60 \mathrm{~Pa}$. This can be attributed to the low periodicity of the disturbances and to the fact that the frequency spectra are derived from a dataset with approximately 5300 blade passings. In the raw data, the disturbance is much more pronounced and has amplitudes of more than $1000 \mathrm{~Pa}$. This has also been addressed in [13].

The following conclusions can be drawn from this paragraph. No rotating instabilities occur at the tightest clearance. The other three investigated clearance sizes showed a rise in frequencies around one-half to one-third of BPF. Thus, the occurrence of RI is not limited to a weakened stage in a multistage compressor but is also detected in a singlestage compressor. The amplitudes of the above-mentioned frequencies rise with increased rotor tip clearance together with a shift towards lower frequencies. Furthermore, it has been shown that the investigated casing grooves are able to influence the rotating instabilities as they reduce their amplitudes in the frequency spectra.
3.4. Time-Resolved Casing Static Pressure. This section discusses time-resolved casing static pressures for all clearance configurations in order to detect a flow pattern that can be linked to the occurrence of rotating instabilities that have been identified in the previous section.

The time-resolved casing static pressures for all clearance configurations are shown in Figures 9 and 10. The data are derived from one sensor array (see Figure 3) at a fixed position on the compressor circumference. It is known from Mailach et al. [13] that RI rotate relative to the rotor with approximately $50 \%$ of rotor speed. The plotted results show snapshots of 10 rotor passages that have passed the measurement position. Snapshots at other instants of time show results that are analogous to the plotted results. Static pressure is depicted by the pressure coefficient which is defined as $c_{p}=$ $\left(p-p_{\infty}\right) /\left(p_{\text {in }}-p_{\infty}\right)$ where $p_{\text {in }}$ is the static pressure at rotor inlet and $p_{\infty}=101325 \mathrm{~Pa}$. The operating point of the SolidWall configurations for the respective clearances is the near stall operating point; the operating point of Groove is identical to SolidWall. The dashed white lines connect the low pressure regions in each plot. These are traditionally linked with the trajectory of the tip leakage vortex. From other investigations (e.g., $[23,24])$ it is known that this is a simplification and that, under certain operating conditions, the near casing flow field shows multiple vortical structures and not one clearly defined tip leakage vortex. This becomes obvious in our results at the largest tested tip clearance that is presented later. 


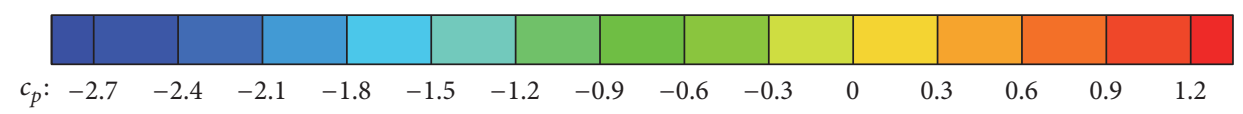

SolidWall $s / c=1.2 \% \xi=0.72$

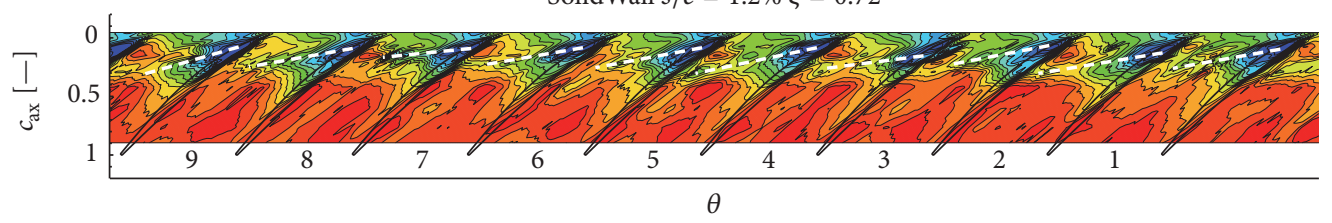

(a)

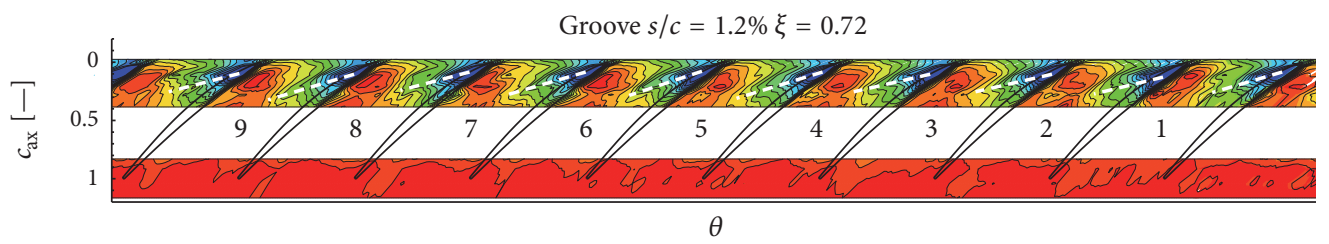

(b)

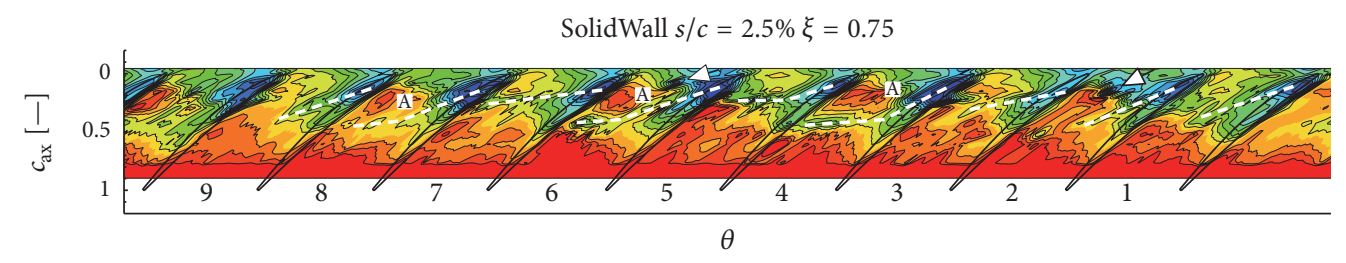

(c)

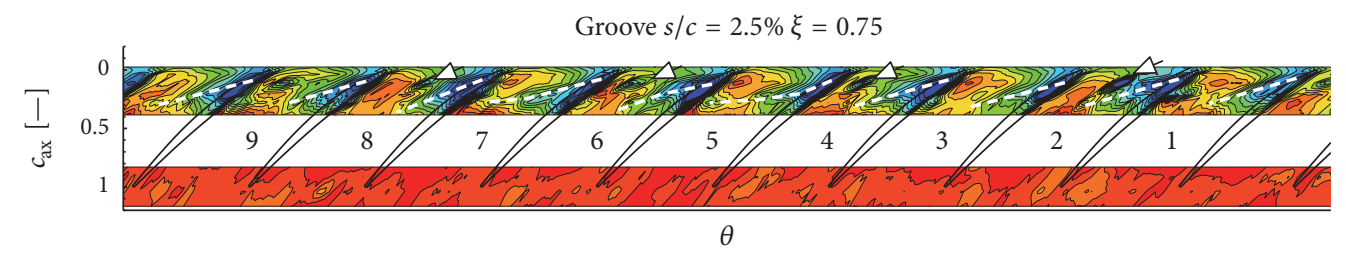

(d)

FIGURE 9: Time-resolved casing static pressure over rotor for SolidWall and Groove at $s / c=1.2 \%(a, b)$ and $s / c=2.5 \%$ (c, d). SolidWall operating points are near stall, Groove operating points identical to SolidWall.

At the smallest tested tip clearance size (Figures $9(\mathrm{a})$ and $9(\mathrm{~b})$ ) the tip leakage vortices start near the leading edge in the region $c_{\mathrm{ax}} \approx 0.1$ at both SolidWall and Groove. The plotted tip leakage vortices of SolidWall slightly differ from passage to passage. In passages 5 and 7 the region of high $c_{p}$ on the blade pressure side is interrupted by a low pressure spot which seems to stem from the tip leakage vortex. In passages 6 and 8, however, these low pressure spots do not appear. These differences are responsible for the increase of standard deviations in Figure 6(c). The Groove configuration of the same clearance size (Figure 9(b)) shows nearly the same flow pattern in each passage. A variation of tip leakage vortex trajectory cannot be detected. The above-mentioned low pressure spots on the blade pressure side vanished. Consequently the standard deviations (see Figure 6(f)) are lower than in SolidWall. It can be concluded that for $s / c=1.2 \%$ tip leakage vortex fluctuations are either small (SolidWall) or not present (Groove), which means that the Groove has a small influence on the near casing flow field that does not lead to an increase in operating range though.

With an increase of tip clearance to $s / c=2.5 \%$ the flow field in SolidWall (Figure 9(c)) is getting more irregular. The differences in vortex trajectory from passage to passage are now easy to detect. Moreover, the region of low $c_{p}$ near the leading edge of the blade now differs strongly in every passage. Although only ten passages are shown in the figures, a repeating pattern can already be detected. Passages 4, 6, and 8 (and partially passage 2 ) all show a high pressure spot around $c_{\mathrm{ax}}=0.25$ on the blade pressure side (see region $\mathrm{A}$ ) and have very similar vortex trajectories. Passages 3, 5, and 7 however show a higher inclination (against axial direction) of the tip leakage vortex trajectory. This change of flow pattern in every other passage that passes the measurement position leads to an increase of amplitudes in the frequency spectra around $0.5 \cdot$ BPF (the frequency spectra for $\xi=0.75$ are not shown here, for brevity, but show an amplitude increase at the same frequencies as the operating point $\xi=0.80$ in Figure 8). 

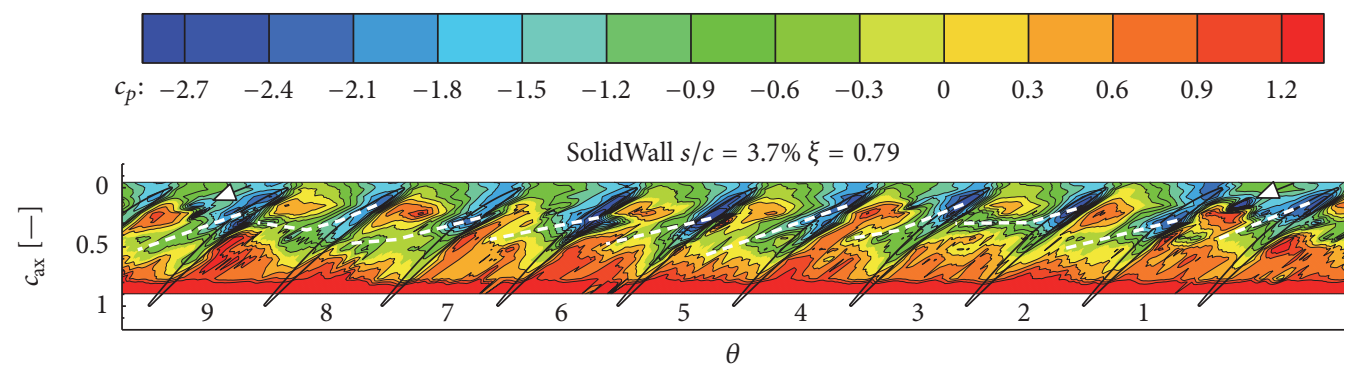

(a)

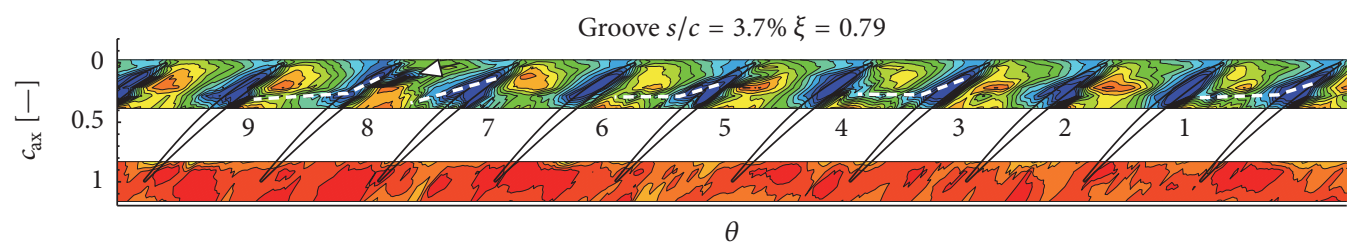

(b)

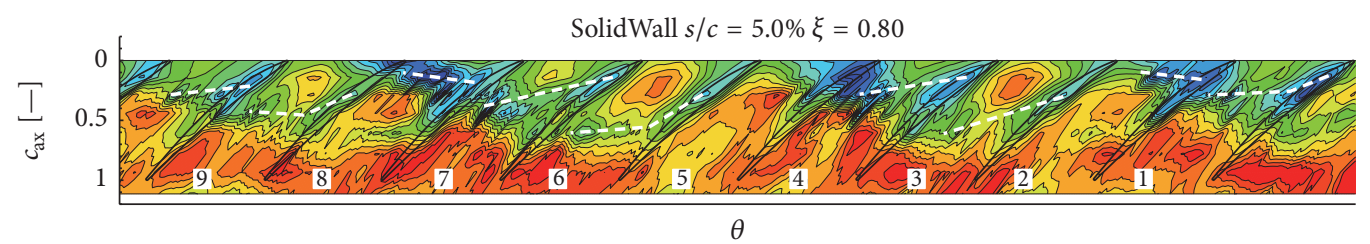

(c)

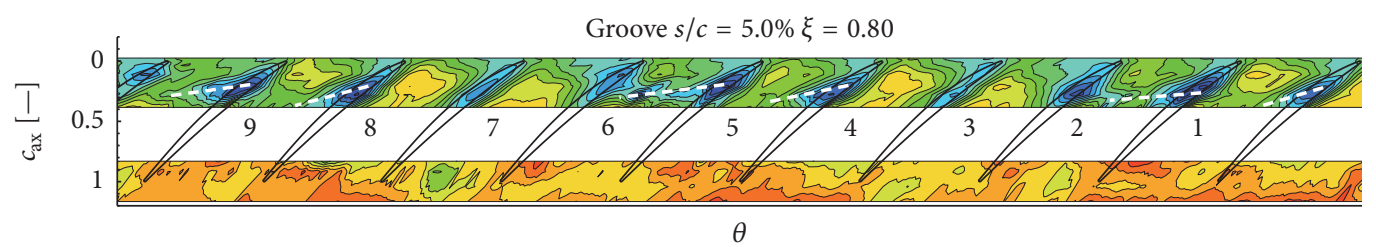

(d)

FIGURE 10: Time-resolved casing static pressure over rotor for SolidWall and Groove at $s / c=3.7 \%(\mathrm{a}, \mathrm{b})$ and $s / c=5.0 \%(\mathrm{c}, \mathrm{d})$. SolidWall operating points are near stall, Groove operating points identical to SolidWall.

The fact that the peak in the frequency spectra around 0.5 . BPF is not sharp but blurred is due to the fact that the above-mentioned pattern is not repeating strictly every other passage but slightly changes.

The black-and-white arrows in passages 2 and 6 mark a low pressure spot which is positioned in the passage between suction side and pressure side of the blade. The source that causes this low pressure spot is not clear. It could be the radial vortex that Hah [25] identified in his investigation which is part of the tip leakage vortex. Inoue et al. [26] and Pullan et al. [27] also identified a radial vortex which stems from blade separation and also produces a low pressure spot in the instantaneous casing pressure. Weichert et al. [28] also linked their observed low pressure spot in the passage near the leading edge with a radial vortex as in $[26,27]$.

The flow field of Groove at $s / c=2.5 \%$ is shown in Figure $9(\mathrm{~d})$. Here, different tip leakage vortex trajectories between the passages can also be observed. The pattern, however, is not as regular as in the SolidWall. In passages 2 and 8 , for example, the trajectories are pretty similar and in both passages a distinct high pressure region near the pressure side exists. The vortex trajectories in passages 7 and 5 seem to reach the pressure side of the blade and thus the above-mentioned area of high pressure is interrupted. The low pressure spots that have been found in SolidWall are also present in Groove. They are again marked by black-and-white arrows. In this case, they appear in passages $2,4,6$, and 8 . This regular appearance, however, is not visible throughout the whole dataset. The authors in [26-28] all linked the appearance of their radial vortices to the formation of a spike that initiated compressor stall. The fact that Figure 9(d) shows the appearance of the low pressure spots at an operating point which is not near stall makes the same mechanism for its appearance as in $[26,27]$ less likely.

At the tip clearance of $s / c=3.7 \%$ the tip leakage vortex fluctuations increase; see Figure 10(a). In passages 3 and 9 the vortex stands nearly vertical in the passage whereas in the other passages it shows a notably lower inclination. Like in $s / c=2.5 \%$, a strong variation of the minimum pressure spot over the blade is present. The blades on the right hand sides 


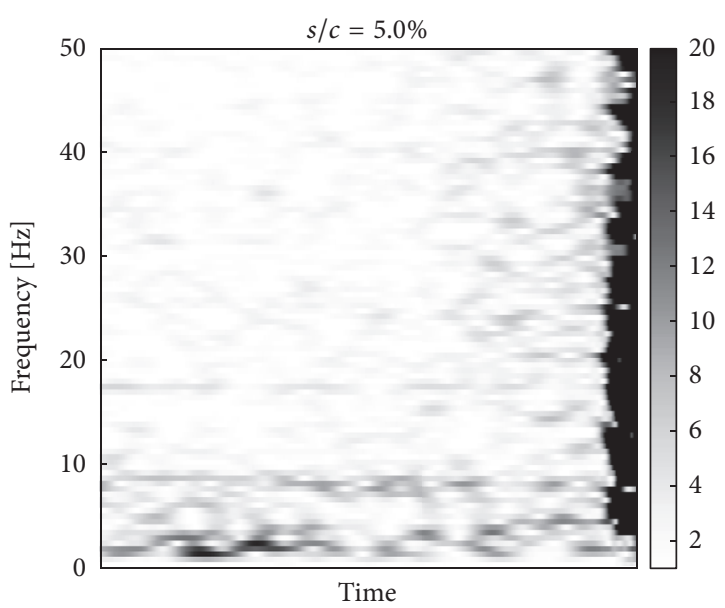

(a)

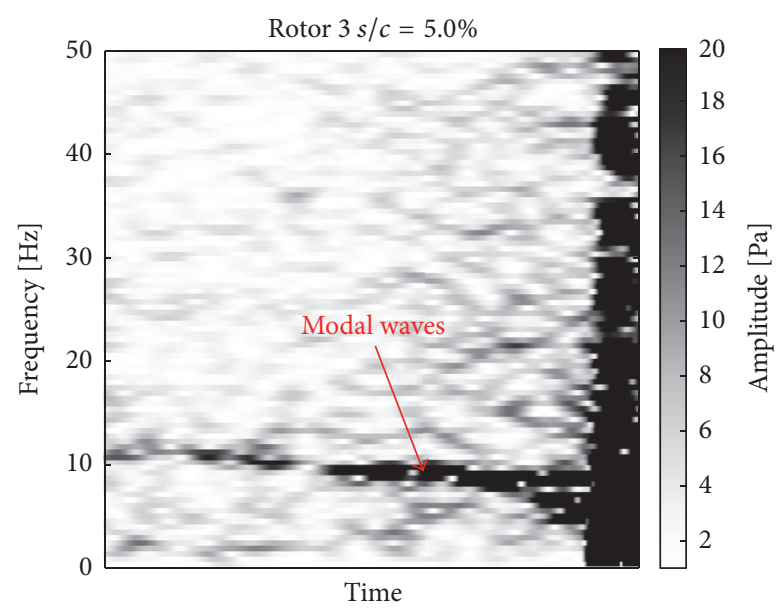

(b)

FIGURE 11: Spectrogram of microphone at $c_{\mathrm{ax}}=-0.2$ (upstream rotor leading edge). (a) $s / c=5.0 \%$ of single-stage test. (b) $s / c=5.0 \%$ only in Rotor 3 of four-stage test.

of passages 2 and 8 both have a position of minimum overblade pressure that is far more downstream than in the other passages. The low pressure spots marked by the arrow again show the potential existence of radial vortices near the blade leading edge. In the Groove configuration (Figure 10(b)) the position of minimum over-blade pressure is identical in each passage, which results in similar starting points of the tip leakage vortex. The position of the Groove makes it difficult to track the vortices in this configuration. It is, however, obvious that vortex fluctuations are still present. The spectral analysis in Figure 8 revealed that the dominant peak has been damped by the Groove. This means that the periodicity of appearance of the vortex fluctuations is unchanged compared to SolidWall, but its amplitudes have been damped.

The increase of rotor tip clearance to $s / c=5.0 \%$ drastically alters the near casing flow field. As mentioned earlier, especially at this tip clearance size, the dashed white lines are a strong simplification of the tip leakage vortex path. The figure suggests that multiple vortical structures are present. The SolidWall (Figure 10(c)) now exhibits very strong tip leakage vortex fluctuations. A periodic pattern can be identified. Starting in passage 3 , the vortex starts around $c_{\mathrm{ax}}=0.3$ and proceeds within the passage. In passage 4 , the starting point of the vortex moved upstream to $c_{\mathrm{ax}}=0.15$. The vortex trajectory is steeper than in passage 3 and the vortex interacts with the pressure side of the adjacent blade around $c_{\mathrm{ax}}=$ 0.3 . Passage 5 then shows a very pronounced low pressure spot near the leading edge and from the measured pressure field the vortex trajectory cannot be estimated anymore. The following passage 6 is similar to passage 3 and the pattern of vortex fluctuation starts again. This pattern is responsible for the increase of amplitudes at frequencies around 0.3. BPF that were identified in Figure 8. In Figure 10(d), Groove configuration, the vortex fluctuations are not as pronounced as in SolidWall. Again, the Groove positions hinder the tracking of the vortex path. In some passages, for example, passages 2 and 6, the vortex is highly inclined against axial direction so that it is proceeding in the passage upstream the
Groove. Passages 8 and 4 and passages 7 and 3 also show very similar patterns upstream the Groove which leads to the assumption that a similar pattern as in SolidWall is present. In both SolidWall and Groove of $s / c=5.0 \%$ the low pressure spots in the passage near the leading edge cannot be identified anymore, or are overlaid by the tip leakage vortex.

3.5. Modal Activities. The total-to-static characteristics in Figure 4 showed a zero slope near stall for SolidWall of $s / c$ $=5.0 \%$ and according to general opinion hint to an existence of modal activities. Therefore in this section the occurrence of modal waves is investigated.

The spectrogram of a single microphone positioned $16 \mathrm{~mm}$ upstream the rotor leading edge is shown in Figure 11 during a slow closing of the throttle into stall. Figure 11(a) shows results of the SolidWall of $s / c=5.0 \%$ whereas Figure 11(b) shows results from third rotor of a four-stage test, where only rotor 3 runs with an increased clearance of $s / c=5.0 \%$. In the case of the weakened stage a distinct disturbance is visible throughout the whole time line which starts at frequencies slightly above $10 \mathrm{~Hz}$ that decrease with further throttling. Mailach [29] showed that these amplitudes are evoked by modal waves in the compressor. In the present single-stage test these disturbances cannot be detected neither at the largest tip clearance (see Figure 11(a)) nor at any other tip clearance size. Furthermore, no influence of the Groove on modal activities could be detected.

The results presented above reveal that the slope of the total-to-static characteristics does not seem to be a sufficient criterion to predict modal waves in an axial compressor.

\section{Conclusions}

In this paper, detailed measurements in a single-stage build of the Low Speed Research Compressor at Technische Universität Dresden have been presented. Four different tip clearance sizes of $s / c=1.2 \%, 2.5 \%, 3.7 \%$, and $5.0 \%$ have been 
investigated with and without a circumferential groove casing treatment. The overall compressor performance as well as the rotor tip flow field have been evaluated. The main conclusions of the paper are as follows:

(i) The present casing groove works well at the three largest tested tip clearance sizes $(s / c=2.5 \%, 3.7 \%$, and $5.0 \%)$. Here, it increases the compressor's operating range and partially the efficiency. At the smallest tested tip clearance size of $s / c=1.2 \%$ the grooves do not exhibit a negative influence on efficiency between design point and stall.

(ii) Results from unsteady wall pressure measurements show that the groove is able to delay the upstream movement of the flow interface between tip leakage and main flow and thereby increases compressor stability.

(iii) The peaks in the frequency spectra in regions around 0.3-0.5. BPF could clearly be linked to rotating instabilities.

(iv) The rotating instabilities increase in amplitude with tip clearance size. At the same time the frequency of appearance in the frequency spectra is decreased because the periodic pattern of RI increases from every other to every third blade passage.

(v) Low pressure spots near the leading edge in the passage have been observed that could be evoked by radial vortices either of the Inoue et al. [26] and Pullan et al. [27] type or by a mechanism described by Hah [25].

(vi) Although the total-to-static characteristics at SolidWall of $s / c=5.0 \%$ show a zero slope near stall, no modal activities could be detected.

\section{Nomenclature}

\section{Greek Symbols}

$\begin{array}{ll}\eta: & \text { Isentropic efficiency } \\ \theta: & \text { Circumferential coordinate } \\ \xi: & \text { Flow rate coefficient } \\ \pi_{t}: & \text { Total pressure ratio } \\ \phi: & \text { Flow coefficient } \\ \Delta \phi_{\text {Stall }}: & \text { Percentage reduction in stall flow coefficient } \\ & \text { relative to smallest tip clearance size } \\ \Psi_{t-s}: & \text { Total-to-static pressure coefficient } \\ \rho: & \left.\text { Density [kg/m }{ }^{3}\right] \\ \sigma_{p}: & \text { Standard deviation of casing wall pressure } \\ \delta: & \text { Clearance derivative. }\end{array}$

\section{Latin Symbols and Abbreviations}

BPF: Blade passing frequency

$c$ : Chord length $[\mathrm{m}]$

$c_{\mathrm{ax}}$ : Nondimensional axial chord length

DP: Design point

$h$ : $\quad$ Depth of casing groove in $\%$ axial chord $h_{\text {total }}:$ Total enthalpy $\left[\mathrm{m}^{2} / \mathrm{s}^{2}\right]$

$i$ : Inclination angle of casing groove $\left[{ }^{\circ}\right]$

is: Isentropic

IGV: Inlet guide vane

LSRC: Low Speed Research Compressor

$\Delta \dot{m}_{\text {Stall }}$ : Percentage reduction of stall mass flow

$\dot{m}$ : Mass flow $[\mathrm{kg} / \mathrm{s}]$

M: Torque [Nm]

MP: Measuring plane

MS: Midspan

$n: \quad$ Shaft speed $[1 / \mathrm{min}]$

$p: \quad$ Static pressure $[\mathrm{Pa}]$

$p_{\text {total }}: \quad$ Total pressure $[\mathrm{Pa}]$

RI: Rotating instabilities

$s: \quad$ Tip clearance size $[\mathrm{m}]$

SW: SolidWall

$T_{\text {total }}: \quad$ Total temperature [K]

TC: Tip clearance

$u$ : $\quad$ Blade speed $[\mathrm{m} / \mathrm{s}]$

$v_{\mathrm{ax}}$ : Axial component of absolute velocity [m/s]

$x_{w}$ : Width of casing groove in $\%$ axial chord

$x_{c}$ : $\quad$ Axial location of casing groove in $\%$ axial chord.

\section{Disclosure}

The responsibility for the content lies solely with its authors.

\section{Conflicts of Interest}

The authors declare that there are no conflicts of interest regarding the publication of this article.

\section{Acknowledgments}

The authors gratefully acknowledge the industrial partner ALSTOM Power for their permission to publish this paper.

\section{References}

[1] D. C. Wisler, "Loss reduction in axial-flow compressors through low-speed model testing," Journal of Engineering for Gas Turbines and Power, vol. 107, no. 2, pp. 354-363, 1985.

[2] N. A. Cumpsty, Compressor Aerodynamics, Krieger Publishing, 2004.

[3] W. M. Osborn, G. W. Lewis, and L. J. Heidelberg, "Effect of Several Porous Casing Treatments on Stall Limit and on Overall Performance of an Axial Flow Compressor Rotor, NASA Technical Note D-6537," Tech. Rep., 1971.

[4] D. C. Prince, D. C. Wisler, and D. E. Hilvers, "Study of Casing Treatment Stall Margin Improvement Phenomena, NASA Report CR 134552," Tech. Rep., 1974.

[5] H. Takata and Y. Tsukuda, "Stall margin improvement by casing treatment - its mechanism and effectiveness," Journal of Engineering for Power, vol. 99, no. 1, pp. 121-133, 1977.

[6] A. Shabbir and J. J. Adamczyk, "Flow mechanism for stall margin improvement due to circumferential casing grooves on axial compressors," Journal of Turbomachinery, vol. 127, no. 4, pp. 708-717, 2005. 
[7] X. Lu, W. Chu, J. Zhu, and Y. Wu, "Mechanism of the interaction between casing treatment and tip leakage flow in a subsonic axial compressor," in Proceedings of the 2006 ASME 51st Turbo Expo, GT2006-90077, pp. 79-90, Barcelona, Spain, May 2006.

[8] V. Perrot, A. Touyeras, and G. Lucien, "Detailed CFD analysis of a grooved casing treatment on an axial subsonic compressor," in Proceedings of the 7th European Conference on Turbomachinery: Fluid Dynamics and Thermodynamics, ETC7-016, March 2007.

[9] M. Rolfes, M. Lange, and K. Vogeler, "Experimental investigation of circumferential groove casing treatments for large tip clearances in a low speed axial research compressor," in Proceedings of the ASME Turbo Expo 2015: Turbine Technical Conference and Exposition, GT2015-42646, Montreal, Quebec, Canada, June 2015.

[10] T. Houghton and I. Day, "Enhancing the stability of subsonic compressors using casing grooves," Journal of Turbomachinery, vol. 133, no. 2, Article ID 021007, 2011.

[11] J. Li, F. Lin, S. Wang, J. Du, C. Nie, and J. Chen, "Extensive experimental study of circumferential single groove in an axial flow compressor," in Proceedings of the Proceeding of the ASME Turbo Expo 2014: Turbine Technical Conference and Exposition, GT2014-26859, Düsseldorf, Germany, June 2014.

[12] I. J. Day, "Stall, surge, and 75 years of research," Journal of Turbomachinery, vol. 138, no. 1, Article ID 2478223, 2015.

[13] R. Mailach, I. Lehmann, and K. Vogeler, "Rotating instabilities in an axial compressor originating from the fluctuating blade tip vortex," Journal of Turbomachinery, vol. 123, no. 3, pp. 453-460, 2001.

[14] J. März, C. Hah, and W. Neise, "An experimental and numerical investigation into the mechanisms of rotating instability," Journal of Turbomachinery, vol. 124, no. 3, pp. 367-375, 2002.

[15] D. Wisler, B. F. Beacher, and H.-W. Shin, "Effects of loading and clearance variation on tip vortex and endwall blockage," in Proceedings of the 9th International Symposium on Transport Phenomena and Dynamics of Rotating Machinery, 10-14 February 2002.

[16] A. Young, I. Day, and G. Pullan, "Stall warning by blade pressure signature analysis," Journal of Turbomachinery, vol. 135, no. 1, Article ID 011033, 2012.

[17] T. R. Camp and I. J. Day, "A study of spike and modal stall phenomena in a low-speed axial compressor," Journal of Turbomachinery, vol. 120, no. 3, pp. 393-401, 1998.

[18] P. Boos, H. Möckel, J. M. Henne, and R. Seimeler, "Flow measurement in a multistage large scale low speed axial flow research compressor," in Proceedings of the ASME 1998 International Gas Turbine and Aeroengine Congress and Exhibition, 98GT-432, Stockholm, Sweden.

[19] M. Künzelmann, R. Müller, R. Mailach, and K. Vogeler, "Steady and unsteady flow field in a multistage low-speed axial compressor - A test case," in Proceedings of the 2008 ASME Turbo Expo, GT2008-50793, pp. 447-455, Berlin, Germany, June 2008.

[20] R. A. Berdanier and N. L. Key, “The effects of tip leakage flow on the performance of multistage compressors used in small core engine applications," Journal of Engineering for Gas Turbines and Power, vol. 138, no. 5, Article ID 052605, 2016.

[21] N. M. McDougall, "A comparison between the design point and near stall performance of an axial compressor," Journal of Turbomachinery, vol. 112, no. 1, pp. 109-115, 1989.

[22] H. D. Vo, C. S. Tan, and E. M. Greitzer, "Criteria for spike initiated rotating stall," Journal of Turbomachinery, vol. 130, no. 1, Article ID 011023, 2008.
[23] D. Tan, Y. Li, H. Chen, I. Wilkes, and J. Katz, "The three dimensional flow structure and turbulence in the tip region of an axial flow compressor," in Proceedings of the ASME Turbo Expo 2015: Turbine Technical Conference and Exposition, GT2015-43385, Montreal, Quebec, Canada, June 2015.

[24] D. Tan, Y. Li, I. Wilkes, R. L. Miorini, and J. Katz, "Visualization and time-resolved particle image velocimetry measurements of the flow in the tip region of a subsonic compressor rotor," Journal of Turbomachinery, vol. 137, no. 4, Article ID 041007, 2015.

[25] C. Hah, "Effects of double-leakage tip clearance flow on the performance of a compressor stage with a large rotor tip gap," Journal of Turbomachinery, vol. 139, no. 6, Article ID 061006, 2017.

[26] M. Inoue, M. Kuroumaru, T. Tanino, and M. Furukawa, "Propagation of multiple short-length-scale stall cells in an axial compressor rotor," Journal of Turbomachinery, vol. 122, no. 1, pp. 45-54, 2000.

[27] G. Pullan, A. M. Young, I. J. Day, E. M. Greitzer, and Z. S. Spakovszky, "Origins and structure of spike-type rotating stall," Journal of Turbomachinery, vol. 137, no. 5, Article ID 051007, 2015.

[28] S. Weichert and I. Day, "Detailed measurements of spike formation in an axial compressor," Journal of Turbomachinery, vol. 136, no. 5, Article ID 051006, 2013.

[29] R. Mailach, Experimentelle Untersuchung von Strömungsinstabilitäten im Betriebsbereich zwischen Auslegungspunkt und Stabilitätsgrenze eines vierstufigen NiedergeschwindigkeitsAxialverdichters [Doctoral thesis], Technische Universität Dresden, 2001. 


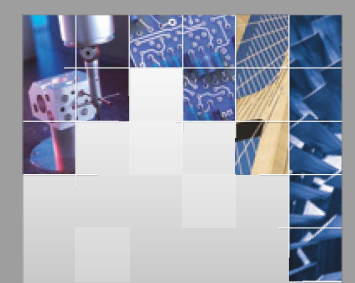

\section{Enfincering}
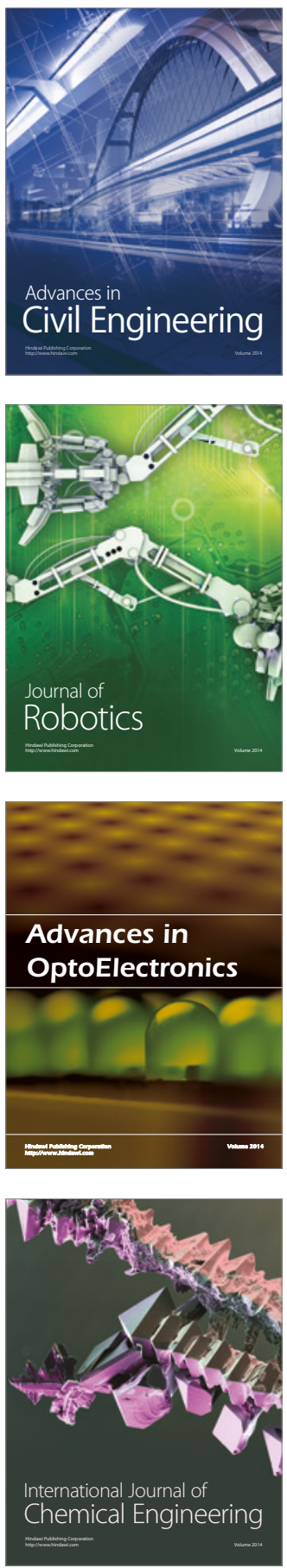

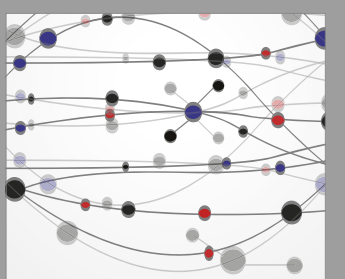

The Scientific World Journal

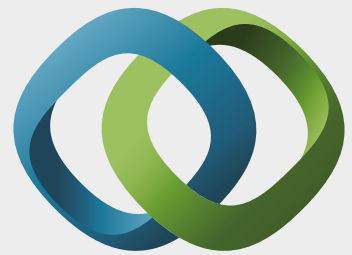

\section{Hindawi}

Submit your manuscripts at

https://www.hindawi.com
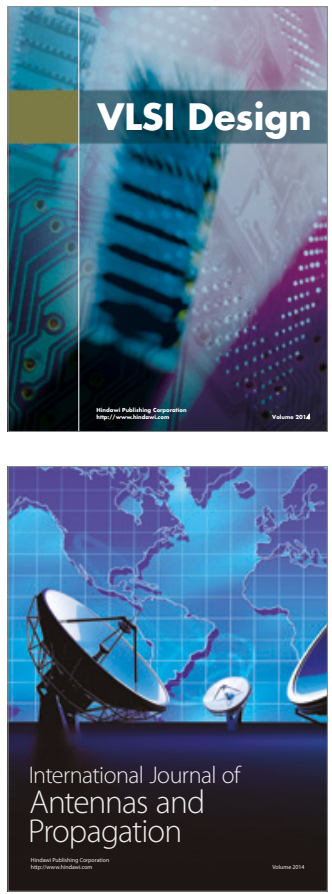

\section{Rotating}

Machinery
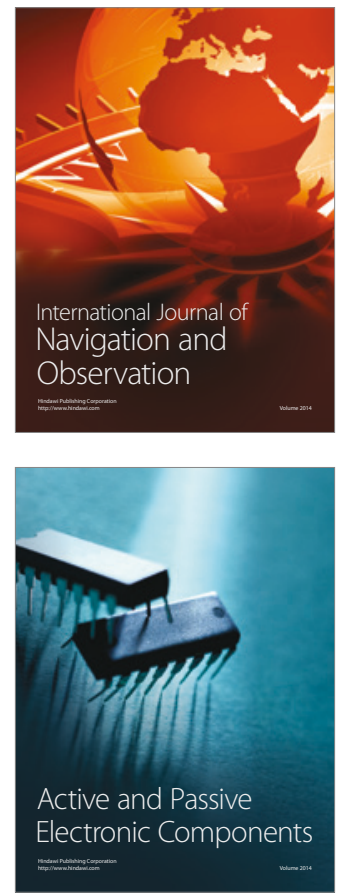
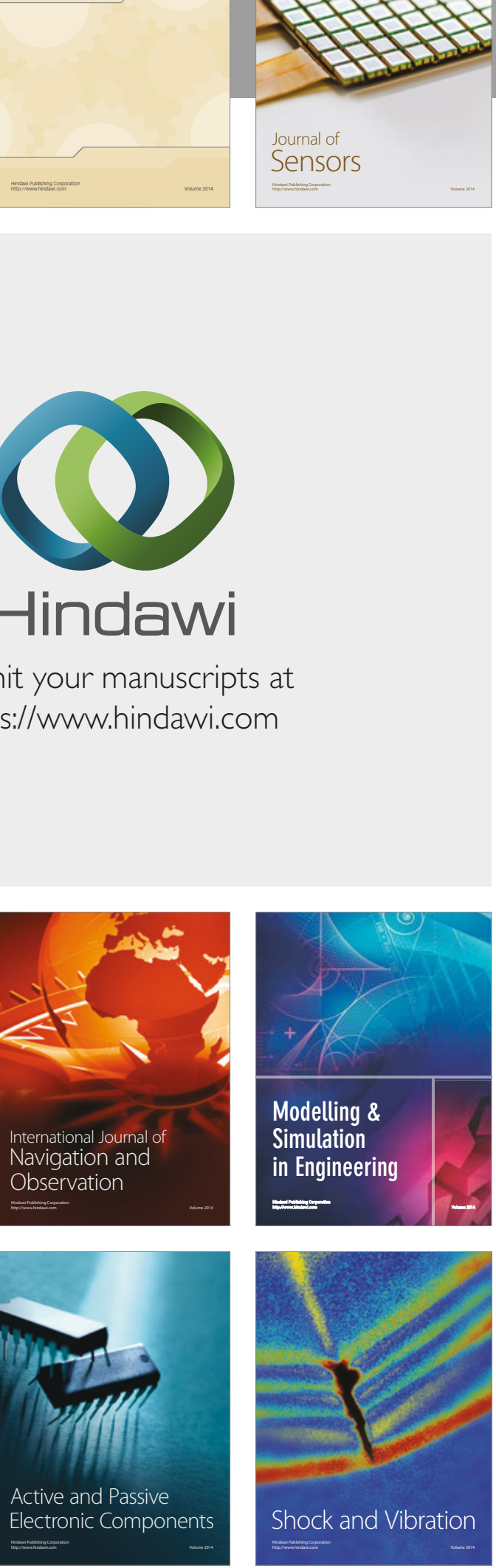
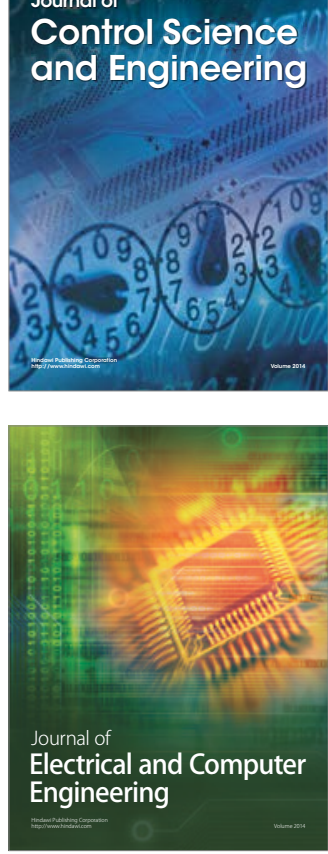

Distributed

Journal of

Control Science

and Engineering
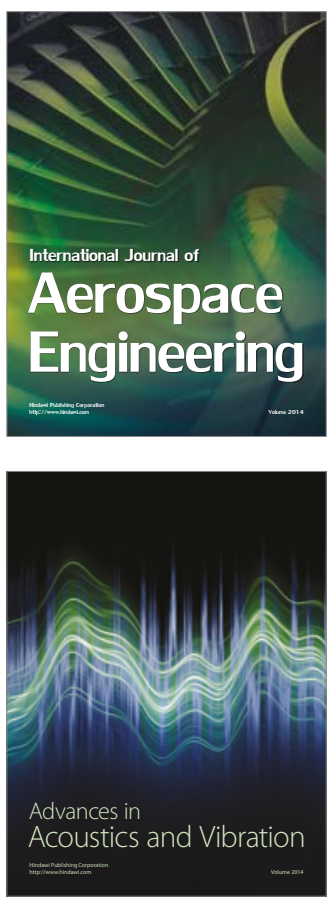

Sensor Networks 